\title{
The Sequential Organ Failure Assessment (SOFA) score: a useful prognostic instrument after cardiac surgery for the elderly patient
}

\author{
S Caroleo ${ }^{1 *}$, F Onorati ${ }^{2}$, O Bruno ${ }^{1}$, D Vuoto $^{1}$, F Infelise ${ }^{1}$, A Rubino $^{2}$, E Santangelo $^{3}$, A Renzulli ${ }^{2}$, B Amantea ${ }^{1}$ \\ From de Senectute: Age and Health Forum \\ Catanzaro, Italy. 5-7 December 2009
}

\section{Background}

Organ dysfunction evaluation using Sequential Organ Failure Assessment score (SOFA score) has been shown to predict mortality and morbidity in adult cardiac surgical patients [1].

\section{Materials and methods}

Design: analysis of a prospectively collected database.

Setting: mixed Intensive Care Unit (ICU) in an University Hospital.

Patients: A total of 70 patients (ASA II-IV) aged $>65$ submitted to cardiac surgery. They were evaluated on 24,48 and 72 hours after ICU admission. All post-operative ASA IV-E ( $\mathrm{E}=$ emergency) and all ICU patients with different diagnosis were excluded from data collection.

Interventions: the collection of raw data necessary for the computation of a SOFA score on 24, 48 and 72 hours after admission and basic demographic and clinical statistics.

Data collection: We collected the parameters in order to calculate the Admission (AD), Daily, Mean, Total Maximum (TM) and Delta $(\Delta)$ SOFA score at the specific time points mentioned above.

\section{Results}

The Admission, TMS score and $\triangle$ SOFA presented a good correlation with mortality [area under the curve 0,9 (SE 0,060) and 0,809 (SE 0,136), respectively]. All the patients that receive more than $2000 \mathrm{ml}$ of intraoperative fluids had an Admission SOFA Score between 16 and $20(\mathrm{p}<0.001)$. All the patients with preoperative Left
Ventricular Ejection Fraction $>45 \%$ had an Admission SOFA Score between 2 and $10(\mathrm{p}<0.001)$. All the patients mechanically ventilated for more than 5 days presented an Admission SOFA score between 17 and 20, while the same score was between 0 and 10 for those successfully extubated after 24 hours $(\mathrm{p}<0.001)$. The mean cardiovascular, coagulation, hepatic, neurological and renal SOFA score were associated with the highest relative contribution to outcome [area under the curve 0,980 (SE 0,028), 0,951 (SE 0,057), 0,927 (SE 0,069), 0,991 (SE 0,019) and 0,944 (SE 0,061), respectively].

\section{Conclusions}

SOFA score is a useful prognostic instrument even in this specific clinical context.

\section{Author details}

'Deparment of Anaesthesia and Reanimation, University of Catanzaro, Catanzaro, Italy. ${ }^{2}$ Department of Cardiac Surgery, University of Catanzaro, Catanzaro, Italy. ${ }^{3}$ Department of Anaesthesia and Oncological Intensive Care, Italy.

Published: 19 May 2010

\section{Reference}

1. Pätilä T, Kukkonen S, Vento A, Pettilä V, Suojaranta-Ylinen R: Relation of the Sequential Organ Failure Assessment score to morbidity and mortality after cardiac surgery. Ann Thorac Surg 2006, 82(6):2072-8.

\section{doi:10.1186/1471-2318-10-S1-A99}

Cite this article as: Caroleo et al:: The Sequential Organ Failure

Assessment (SOFA) score: a useful prognostic instrument after cardiac surgery for the elderly patient. BMC Geriatrics 2010 10(Suppl 1):A99. 